\title{
Experimental Investigation of Injection Pressure Effect on the Natural Gas Storage in Aquifers
}

\author{
E. Kazemi Tooseh, A. Jafari, and A. Teymouri
}

\begin{abstract}
Storing natural gas in underground reservoirs is a key element in the gas supply market. Depleted oil and gas reservoirs, salt caverns and aquifers are major candidates for natural gas storage, and between them aquifers have a high potential for effective balancing of a variable demand market. Aquifers are underground water bearing formations which may extend over distances of several miles, and in the absence of depleted reservoirs, saline aquifers are a proper option for underground gas storage. Because of water and gas movements in the reservoir, it is worth to know about the flow behavior across the porous medium. The behavior of natural gas in contact with brine has not been considered widely in the literature, and the effect of injection pressure on the process has not been studied experimentally before. Therefore, for the first time in this research the natural gas storage capacity at different pressures were calculated and gas and water flow behavior under high injection pressures in a low permeability rock is investigated by experimental tests.

Natural gas flooding experiments were performed using a core flood set up at constant temperature $46^{\circ} \mathrm{C}$, and in each test the low permeability core sample taken from an Iranian aquifer was cleaned by methanol injection for 24 hours. Then it was dried in oven at $90^{\circ} \mathrm{C}$ for 12 hours. After that the core was vacuumed for 8 hours and saturated by two pore volume of the synthetic brine with $210000 \mathrm{ppm}$ salt concentration. After that natural gas was injected at a constant flow rate into the core plug saturated with brine, and at the gas breakthrough time experiments were stopped and the storage capacity of sample was measured by comparing its weight difference before and after the test. Obtained results illustrate that the injection pressure plays an important role in the gas storage process, and increasing the pressure improves the sweep efficiency and water withdrawal. In other words, by doubling the injection pressure from 80 to 160 bar the gas storage capacity enhances about $7 \%$.
\end{abstract}

Index Terms-Natural gas, storage, aquifer, pressure effect.

\section{INTRODUCTION}

Underground gas storage (UGS) is a concept which has evolved the effective balancing of a variable demand market. Historically, UGS was introduced for the first time in 1915 at an operating gas field in Canada. But rapidly UGS facilities were developed, and recently researchers have focused on underground natural gas storing during the low consumption

Manuscript received August 11, 2017; revised November 20, 2017. This work was supported by the Natural Gas Storage Company of Iran.

E. Kazemi Tooseh is with National Iranian Oil Company, Tehran, Iran (e-mail: esmaeelkazemi69@gmail.com).

A. Jafari is with Tarbiat Modares University, Tehran, Iran (e-mail: ajafari@modares.ac.ir).

A. Teymouri is with National Iranian Gas Company, Tehran, Iran (e-mail: teymouri@nigc.ir). seasons [1]. In other words, gas storage is now considered as a key element for the gas supply market and has been used to satisfy a number of needs [2]. The whole natural gas storage process is comprised of injecting the gas into a subsurface reservoir during periods that demand falls below the gas supply. When consumption exceeds the supply, the gas will be withdrawn from the reservoir, and it is possible to have an effective delivery during the demand peak [3]. This process can also be adapted to produce oil or condensate and can be considered as an improved oil recovery (IOR) method [4].

Depleted oil and gas reservoirs, salt caverns and aquifers are major candidates for storing natural gas. Aquifers are underground water bearing formations which may extend over distances of several miles. When a closed anticlinal structure exists in an aquifer, it is possible to inject and store natural gas in the upper portion of the aquifer [5]. Because of the strong water drive in these reservoirs, it is reasonable to consider the important parameters in this process. But there are few related researches in the literatures, so the effective parameters are not well studied [6]. There are various parameters engaged in the gas storage process such as injection pressure, flow rate, brine salinity, temperature and reservoir rock properties. Salinity and temperature are not affected in a huge aquifer during gas storage [7], [8] but injection pressure and gas flow rate are more operative and interesting to be studied. Usually when encountering a flow of gas, the pressure of the system may affect the gas phase behavior very much. In the case of natural gas, increase of pressure changes the gas behavior toward the liquid flow. Abdollahi et al. [9] developed a compositional simulation model and showed that the injection pressure of gas is very effective on storage capacity during the gas storage process. Also other researchers have performed different simulations on natural gas storage process. Golghanddashti et al. [10] studied the gas storage in a depleted gas reservoir with edge aquifer at ambient pressure and high flow rates. Also Chun et al. investigated the gas storage process at atmospheric pressure. Sohrabi et al. [11] evaluated the multiphase flow and gas phase sweep efficiency during water alternating gas process. Billiotte et al. [12] studied numerically the injection withdrawal cycles and the flow rate effect in underground gas storage reservoir, and they have simulated air-water displacement in a micromodel.

As literature illustrates there has not been any experimental study on high pressure natural gas storage in saline aquifers. So in this study for the first time the influence of gas injection pressure on storage of natural gas in saline aquifers has been investigated experimentally. Three core flood experiments have been done on a core plug, and the fully brine saturated 
sample is turned to a gas storage reservoir and the storage capacity of rock is calculated in each experiment.

\section{EXPERIMENTAL PROCEDURE}

One core sample with length and diameter 3 and 1.5 inches, respectively was taken from an Iranian aquifer reservoir candidate for natural gas storage. The porosity and permeability of the core sequentially are $8.32 \%$ and $0.09 \mathrm{md}$. Table I specifies the core plug characteristics used in this research.

\begin{tabular}{cccc}
\multicolumn{4}{c}{ TABLE I: SPECIFICATION OF ROCK CORE USED IN THIS STUDY } \\
\hline $\begin{array}{c}\text { Porosity } \\
(\%)\end{array}$ & $\begin{array}{c}\text { Air } \\
\text { Permeability } \\
\text { (md) }\end{array}$ & $\begin{array}{c}\text { Length } \\
\text { (inch) }\end{array}$ & $\begin{array}{c}\text { Diameter } \\
\text { (inch) }\end{array}$ \\
\hline 8.32 & 0.09 & 3 & 1.5
\end{tabular}

Injected gas is the domestic gas which mainly consists of methane, and its combination is analyzed by the gas chromatography analysis. In order to measure non hydrocarbon gases along with hydrocarbon gases, TCD detector is deployed, and the gas chromatography analysis is done using TGF gas chromatograph model no.2550TG. Result of gas chromatography analysis is shown in Fig. 1. The injected gas consists of $98.98 \%$ methane and $1.02 \% \mathrm{CO}_{2}$. The analysis is repeated twice in order to be sure that measurements are accurate. As it is shown in Fig. 1, there are two groups of peaks, the first two peaks refer to methane and the last one belongs to carbon dioxide. It should be noted that the first two peaks are adjacent because of high concentration of methane in the injected gas.

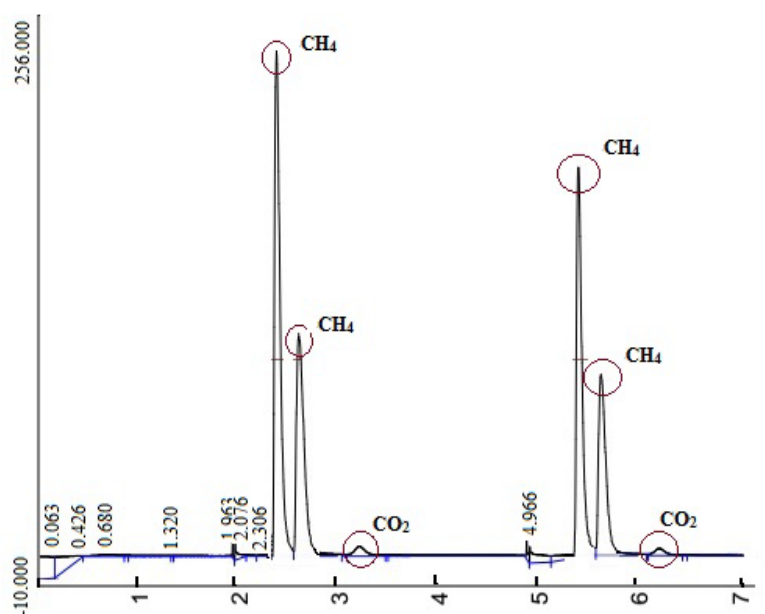

Fig. 1. Results of TCD gas chromatography.

In order to ensure that the feed gas composition is the same as studying reservoir condition (domestic gas), natural gas was provided from the domestic gas line in laboratory. Also in order to fill the gas transfer vessel, natural gas was passed and pressurized through compressor and gas booster. The pressure of domestic gas line is about 1 bar, so in order to fill the feed vessel a multi cycle injection method was designed. At first, gas was passed through a compressor and pressurized up to 3 bar, and then it was passed through the booster to get a pressure equal to $30 \mathrm{bar}$. The pressurized gas was stored in a transfer vessel and it was displaced to another one after injecting water to the bottom part by pump. The cycle was repeated for three times to get a fully charged transfer vessel by high pressure natural gas. Fig. 2 shows the gas charging setup.

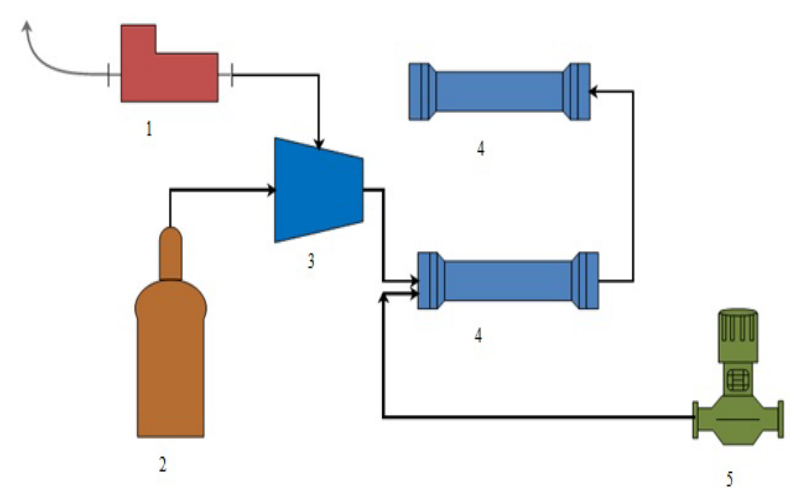

Fig. 2. Schematic of the designed setup for providing natural gas from the domestic gas line (1. Air Compressor, 2. Nitrogen Cylinder, 3. Gas Booster, 4 Transfer Vessel, 5. Pump).

Gas production rate was measured by using a simple water displacement setup. The setup consists of a cylinder with length equal to 1 meter and diameter equal to $9 \mathrm{~cm}$. First it was vacuumed and filled with water. When gas entered the cylinder, water was displaced and the produced gas volume was measured by recording the water level change. Also production rate was measured by dividing the produced volume to water displacing time.

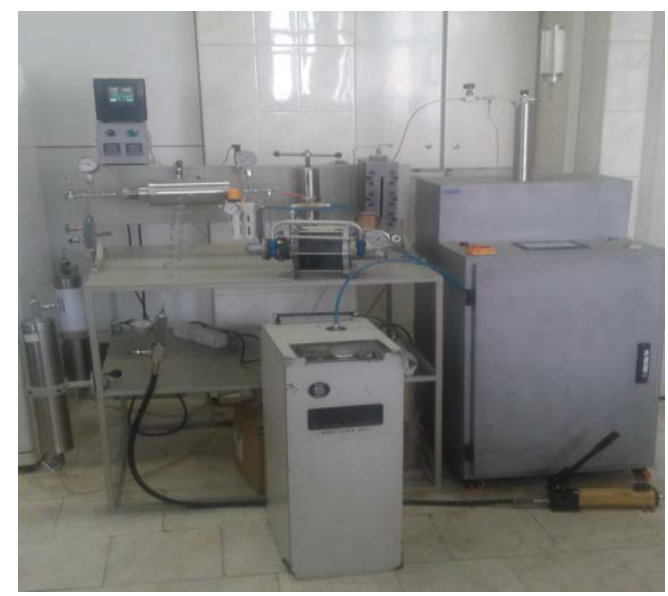

Fig. 3. Gas storage setup used in this study.

The main experimental setup mainly consists of a high pressure positive displacement pump, gas and water transfer vessels, core holder, hydraulic over burden pressure pump, heater, mixing valve, pressure transducers, back pressure regulator and separator. Fig. 3 shows the experimental setup used in this research. In each experiment the core sample was cleaned by injecting two pore volume of methanol, and then it was dried in oven at $90^{\circ} \mathrm{C}$ for 12 hours. After that the sample was vacuumed for 8 hours (because of its low permeability) and saturated by two pore volumes of the synthetic brine with density equal to $1.095 \mathrm{gr} / \mathrm{cc}$ and compositions illustrated in Table II.

The saturated core plug weight was measured, then it was 
wrapped in aluminum foil in order to inhibit the gas flow out of the core sample and the synthetic brine was injected at the constant rate $0.05 \mathrm{cc} / \mathrm{min}$ in order to increase the pressure to the test value. Finally natural gas was injected in a typical flow rate condition and gas-water displacement under high pressure equilibrium occurred. The temperature of the system was set to $46{ }^{\circ} \mathrm{C}$, which is the same as the studying reservoir condition. After injecting two pore volumes of gas and no water production, the sample was held under the constant pressure for 24 hours. Meanwhile gas production rate was measured, and the calculated rates were transformed to experiment pressure by using the ideal gas law (Eq. (1)). In addition, the gas effective permeability was calculated for each experiment using Darcy law (Eq. (2)).

\begin{tabular}{c|ccccccc}
\multicolumn{7}{c}{ TABLE II: BRINE COMPOSITION USED HERE } \\
\hline \hline Ion Name & $\mathrm{Na}^{+}$ & $\mathrm{Ca}^{2+}$ & $\mathrm{K}^{+}$ & $\mathrm{Mg}^{2+}$ & $\mathrm{Cl}^{-}$ & $\mathrm{SO}_{4}{ }^{2-}$ \\
\hline $\begin{array}{c}\text { Concentration } \\
(\mathrm{ppm})\end{array}$ & 30820 & 45740 & 640 & 1580 & 130820 & 400 \\
\hline \hline
\end{tabular}

At the end, core rock weight was measured and storage capacity was calculated by the mean of weight difference before and after the test using equations (3) and (4). It should be mentioned that for having an accurate estimation of stored gas volume, weight measurement suggests the best case. As noted by many authors [13]-[15], natural gas solubility is very little in water even at high pressure, so trapping in aqueous phase is out of concern in this topic and the only way for gas storage is water removal.

$$
P V=Z n R T
$$

where $Q$ is flow rate in cc/s, $K$ is permeability in darcy, $A$ is cross section in $\mathrm{cm}^{2}, \mu$ is viscosity, $d P$ is pressure difference and $L$ is the length.

$$
Q=\frac{K A}{\mu} \frac{d P}{L}
$$

where $Q$ is flow rate in cc/s, $K$ is permeability in darcy, $A$ is cross section in $\mathrm{cm}^{2}, \mu$ is viscosity, $d P$ is pressure difference and $L$ is the length.

$$
\begin{gathered}
V_{b}=\frac{m_{b}}{\rho_{b}} \\
m_{b}=m_{1}-m_{2}
\end{gathered}
$$

In these equations, $V_{b}, m_{b}$ and $\rho_{b}$ are volume, mass and density of produced brine, $\mathrm{m}_{1}$ and $\mathrm{m}_{2}$ stands for saturated core weight and core weight after the gas injection. Using these two equations yield volume of produced brine in the experiment. Then the stored gas volume will be the same as produced brine volume.

\section{RESULTS AND DISCUSSION}

At first two experiments were done in order to investigate the retention time effect on the gas storage. For the first experiment core sample was held under experimental condition for 5 days and in the second experiment retention time duration was set to 1 day. After measuring the storage gas volume no significant difference was observed. So 1 day retention time was selected for remaining experiments, and all measurements were done based on 1 day retention time. Table III shows the results of two experiments, and as the table illustrates the storage volume difference between two tests is about $1 \%$ which is negligible.

TABLE III: RETENTION TIME EFFECT ON GAS STORAGE CAPACITY

\begin{tabular}{ccccc}
\hline \hline $\begin{array}{c}\text { Retention } \\
\text { Time }\end{array}$ & $\begin{array}{c}\text { Flow Rate } \\
\text { (cc/min) }\end{array}$ & $\begin{array}{c}\text { Pressure } \\
\text { (bar) }\end{array}$ & $\begin{array}{c}\text { Storage } \\
\text { Volume } \\
\text { (cc) }\end{array}$ & $\begin{array}{c}\text { Storage } \\
\text { (\%) }\end{array}$ \\
\hline 5 days & 0.05 & 160 & 0.987 & 13.67 \\
1 day & 0.05 & 160 & 0.913 & 12.64 \\
\hline \hline
\end{tabular}

The effect of injection pressure on natural gas storage was investigated by injecting the gas at three typical pressures. It is worthy to note that due to low permeability of the core sample, the injection flow rate is very low, and it was set to $0.05 \mathrm{cc} / \mathrm{min}$. Much care should be taken into account when the injection flow rate is constant. Injection gas flow rate could affect gas flow and gas storage volume. At high flow rates there is less time to fully observe the effectiveness of gas pressure on brine displacement. So choosing a suitable flow rate is very important for investigating the injection pressure effect. Rock permeability is one of the main factors for selecting the injection rate. Here the injection rate $0.05 \mathrm{cc} / \mathrm{min}$ has been chosen in order to have a continuous flow while considering the gas behavior under high pressure in the porous medium.

Three constant flow rate experiments were done at $46{ }^{\circ} \mathrm{C}$, and they were performed at the injection pressures 80, 120 and 160 bar. Core weight measurements presented that there is more weight loss at higher pressures. In addition, as it can be seen in Table IV, higher injection pressure leads to higher gas production rate. On the other hand gas viscosity increases by increasing the injection pressure.

TABLE IV: Gas Production Rate AND EfFective Permeability MEASUREMENT

\begin{tabular}{ccccc}
\hline $\begin{array}{c}P \\
(\mathrm{bar})\end{array}$ & $\begin{array}{c}d p \\
(\mathrm{~atm})\end{array}$ & $\begin{array}{c}\mu \\
(\mathrm{cp})\end{array}$ & $\begin{array}{c}Q \\
(\mathrm{cc} / \mathrm{s})\end{array}$ & $\begin{array}{c}K \\
(\mathrm{md})\end{array}$ \\
\hline 80 & 0.435 & 0.0135 & 0.0117 & 0.0121 \\
120 & 0.694 & 0.015 & 0.0143 & 0.0103 \\
160 & 1.12 & 0.0168 & 0.0218 & 0.0109 \\
\hline \hline
\end{tabular}

Comparison of obtained results illustrated in Table IV and Table V confirms that more effective permeability would not certainly yield more storage percentage. Because there are various factors controlling the permeability such as gas phase and flow behavior. It can be observed that effective permeability at 80 bars is more than others, but the storage percentage is lower in this experiment.

Natural gas which mainly consists of methane shows a gaseous phase behavior even at high pressures. As the injection pressure enhances, density and viscosity of the gas 
phase increases. This leads to lower mobility and a better piston-like displacement. So in the case of gas injection into an aquifer, by increasing the flooding pressure the gas phase sweep efficiency enhances. In other words, as Table $\mathrm{V}$ illustrates, by improving the injection pressure from 80 to 160 bar the storage capacity enhances from $5.78 \%$ to $12.64 \%$. According to the results, enhancing the injection pressure from 120 to 160 bar has increased the stored gas volume about $5 \%$ while pressure enhance from 80 to 120 bar has improved the storage volume about $2 \%$. It can be concluded that higher pressures have more effect on the gas phase behavior and at 160 bar the gas flow is getting closer to a liquid-like piston displacement.

\begin{tabular}{ccccc} 
TABLE V: INJECTION PRESSURE EFFECT ON GAS STORAGE CAPACITY \\
\hline $\begin{array}{c}\text { Experiment } \\
\text { No. }\end{array}$ & $\begin{array}{c}\text { Flow Rate } \\
\text { (cc/min) }\end{array}$ & $\begin{array}{c}\text { Pressure } \\
\text { (bar) }\end{array}$ & $\begin{array}{c}\text { Storage } \\
\text { Volume } \\
\text { (cc) }\end{array}$ & $\begin{array}{c}\text { Storage } \\
\text { (\%) }\end{array}$ \\
\hline 1 & 0.05 & 80 & 0.417 & 5.78 \\
2 & 0.05 & 120 & 0.552 & 7.64 \\
3 & 0.05 & 160 & 0.913 & 12.64 \\
\hline \hline
\end{tabular}

It should be mentioned that by increasing the injection pressure, the cap rock failure pressure should be taken into account. If the reservoir pressure increases too much, integrity of cap rock weakens and there will be a path for gas leakage out of the reservoir.

\section{CONCLUSION}

In order to perform natural gas storage properly, more attention should be paid to all the aspects of this process. As water and gas displacement across a reservoir is affected by operating conditions, in this study the injection pressure was studied through core flood experiments. Obtained data showed that increasing the pressure improves the sweep efficiency and water withdrawal. In this study increasing the injection pressure has improved the gas storage volume of the rock about $7 \%$. But there would be a limit for pressure and choosing the injection pressure depends on many factors.

\section{ACKNOWLEDGMENT}

The authors appreciate Natural Gas Storage Company of Iran for the valuable support and encouragement during this research.

\section{REFERENCES}

[1] A. Khaksar, A. White, K. Rahman, et al., "Geomechanical evaluation for short term gas storage in depleted reservoirs," presented at the 46th US Rock Mechanics/Geomechanics Symposium. Chicago, Illinois, USA, June 24-27, 2012.

[2] K. Aminian and S. D. Mohaghegh, Natural Gas Storage Engineering, first edition, Oxford: Eolss Publishers, 2009.

[3] D. L. Katz and R. L. Lee, Natural Gas Engineering: Production and Storage, first edition. New York: McGraw-Hill Economics Department, 1990.

[4] M. Soroush and N. Alizadeh, "Underground gas storage in partially depleted gas reservoir," presented at Canadian International Petroleum Conference, Calgary, Canada, June 12-14, 2007.
[5] W. K. Sawyer, M. D. Zuber, and A. D. Bues, "Reservoir simulation and analysis of the sciota aquifer gas storage pool," presented at SPE Eastern Regional Meeting, Pittsburgh, Pennsylvania, USA, November 9-11, 1998.

[6] L. Chun, W. Jieming, X. Hongcheng, et al., "Study on fluids flow characteristics of water-gas mutual flooding in sandstone underground gas storage with edge water," presented at International Petroleum Technology Conference, Beijing, China, March 26-28, 2013.

[7] P. Sadirli, A. Jafari, S. Sadeghnejhad, et al., "Simulation and sensitivity analysis of natural gas storage in aquifers in presence of horizontal well," presented at the Fourth Conference on Reservoir Engineering and Upstream Industries, Tehran, Iran, 28 May, 2015.

[8] P. Sadirli, A. Jafari, S. Sadeghnejhad, et al. "Simulation of natural gas storage process in aquifers," presented at the First National Conference on Oil and Gas Fields Development, Tehran, Iran, January 28-29, 2015.

[9] A. Abdollahi, M. Riazi, and S. Ayatollahi, "Investigation of gas storage feasibility in an iranian aquifer," presented at the First Technical Conference and Exhibition on Petroleum, Tehran, Iran, May 14-16, 2013.

[10] H. Golghanddashti, M. Saadat, S. Abbasi, et al., "Experimental investigation of salt precipitation during gas injection into a depleted gas reservoir," presented at the International Petroleum Technology Conference. Bangkok, Thailand, February 7-9, 2011.

[11] M. Sohrabi, D. H. Tehrani, A. Danesh, et al., "Visualization of oil recovery by water-alternating-gas injection using high-pressure micromodels," SPE J., vol. 9, no. 3, pp. 290-301, 2004.

[12] J. A. Billiotte, H. D. Moegen, and P. Oren, "Experimental micromodeling and numerical simulation of gas/water injection/withdrawal cycles as applied to underground gas storage," SPE Advanced Technology Series vol. 1, no. 1, pp. 133-139, 1993.

[13] Z. Duan and S. Mao, "A thermodynamic model for calculating methane solubility, density and gas phase composition of methane-bearing aqueous fluids from 273 to 523k and from 1 to 2000 bar," Geochim. Cosmochi. Acta, vol. 70, no. 13, pp. 3369-3386, 2006.

[14] Z. Duan, N. Møller, J. Greenberg, et al., "The prediction of methane solubility in natural waters to high ionic strength from 0 to $250 \mathrm{c}$ and from 0 to 1600 bar," Geochim. Cosmochi. Acta, vol. 56, no. 4, pp. 1451-1460, 1992.

[15] R. Sun, W. Hu, and Z. Duan, "Prediction of nitrogen solubility in pure water and aqueous nacl solutions up to high temperature, pressure, and ionic strength,” J. Solut. Chem., vol. 30, no. 6, pp. 561-573, 2001.

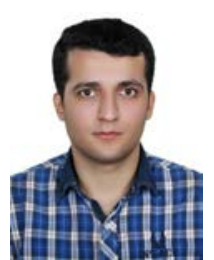

Esmaeel Kazemi Tooseh born in 1990. Kazemi holds a BS degree in petroleum engineering from Petroleum University of Technology, Ahvaz, Iran at 2013 and a MS degree in petroleum engineering from Tarbiat Modares University, Tehran, Iran at 2016.

He has worked on gas storage project in one of Iran's gas storage reservoirs. He is currently with National Iranian Oil Company.

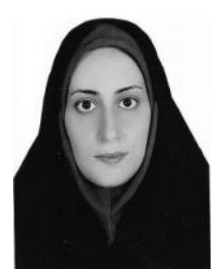

Arezou Jafari holds a BS degree in chemical engineering from Isfahan University of Technology, Isfahan, Iran and a MS degree in chemical engineering from Sharif University of Technology, Tehran, Iran and a $\mathrm{PhD}$ degree in chemical engineering (transport phenomena in porous media) from Lappeenranta University of Technology, Finland.

She is an assistant professor at Tarbiat Modares University. Her research area includes fluid flow in porous media, CFD simulation of fluid flow and chemical processes, enhanced oil recovery, gas storage and reservoir simulation.

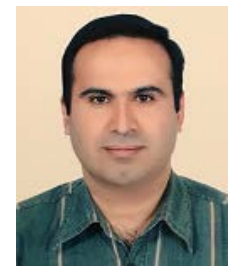

Ali Teymouri holds a BS degree in petroleum engineering from Petroleum University of Technology in 1995 and a MS in reservoir engineering from University of Calgary in 2002.

$\mathrm{He}$ is a senior reservoir engineering who has been working in different subsidiaries of National Iranian Oil Company as reservoir engineer, petro-physics, researcher, execution activities to grow personal and professional brands. After spending nearly a two decades working in upstream activities, he knows what truly drives oil and gas fields' recovery through challenges. 